\title{
Patterns of suicide by occupation in England and Wales: 2001-2005
}

\author{
Howard Meltzer, Clare Griffiths, Anita Brock, Cleo Rooney and Rachel Jenkins
}

\section{Background}

Suicide rates vary by occupation but this relationship has not been frequently studied.

\section{Aims \\ To identify the occupations with significantly high suicide rates in England and Wales in 2001-2005 and to compare these with rates from previous decades.}

\section{Method}

Mortality data from death registrations in England and Wales over the calendar years 2001-2005 were used to calculate proportional mortality ratios (PMRS) and standardised mortality ratios (SMRS) for both men and women aged 20-64 years by their occupation.

\section{Results}

Among men, in 2001-2005, construction workers, and plant and machine operatives had the greatest number of suicides.
The highest PMRs were for health professionals $(P M R=164)$ and agricultural workers (PMR=133). Among women, administrative and secretarial workers had the greatest number of suicides yet the highest PMRs were found for health $(P M R=232)$, and sport and fitness (PMR=244) occupations.

\section{Conclusions}

Excess mortality from suicide remains in some occupational groups. The apparent changes in suicide patterns merits further exploration, for example examining the prevalence of depression and suicidal ideation in medical practitioners, dentists, veterinarians, agricultural workers, librarians and construction workers.

\section{Declaration of interest}

None.
Although the relationship between suicide and unemployment has been extensively studied ${ }^{1-4}$ demonstrating an increased rate of suicide among the unemployed, the relationship between suicide and occupation has been much less frequently studied, probably because of the relatively smaller number of people in each occupational group compared with the population in other socio-demographic groups defined, for example, by age or geography. Mortality data collated by the Office for National Statistics (ONS) in England and Wales have, however, been an invaluable source for examining the relationship between suicide and occupation. ${ }^{5-8}$ In the late 1990s these findings were updated to cover trends in suicide in England and Wales, and suicide data for 1982-1987 and 19911996 were used to calculate proportional mortality ratios (PMRs) for both men and women according to their occupation. ${ }^{9}$

In addition to the national statistics describing the relationship between occupation and suicide, a number of studies have looked in more detail at some of the specific occupations with high suicide PMRs. These included health-related occupations such as doctors, ${ }^{10-12}$ nurses, ${ }^{13}$ farmers (including horticulturalists and farm managers), ${ }^{14}$ armed forces, ${ }^{15}$ students ${ }^{16,17}$ and artists. ${ }^{18,19}$

We aim to identify the occupations in 2001-2005 with significantly high suicide rates in England and Wales, and to compare these with patterns in suicide rates by occupation over earlier decades. The data from 2001-2005 can be regarded as a further update with the possibility of examining the stability of patterns.

\section{Method}

Using data collected by the ONS from death registrations in England and Wales over the calendar years 2001-2005, PMRs were calculated for suicides by occupation. Standardised mortality ratios (SMRs) were also calculated.

The ONS usually classifies deaths from suicide as those with an underlying cause of suicide or death from injury or poisoning of undetermined intent. These latter deaths are traditionally assumed to be probable suicides for the purposes of calculating the number of suicides in England and Wales. ${ }^{20}$ The ICD-10 was used to code cause of death based on coroners' verdicts. ${ }^{21}$ Grouping both deaths from suicide and undetermined intent together to give an estimate of suicides removes biases that may be introduced if there are differences between occupations in the propensity of coroners to record a suicide verdict.

The deceased's occupation is collected from the informant at death registration and is based on the last gainful occupation of the deceased if they were retired or unemployed. This is then coded by the ONS using the Standard Occupational Classification 2000 (SOC2000). ${ }^{22}$ This contains 352 occupation codes at its lowest (four-digit) level. Data from the 2001 Census were also coded using the SOC2000, and are based on the occupation of respondents in the week before census, or their last occupation in the past 5 years not working. We restricted our analysis to the age range 20-64 years to improve the likely comparability between occupation recorded at census and at death registration.

The PMR is a ratio of how more or less likely a death in a given occupation is to be from suicide as opposed to other causes, than a death of someone of the same age and gender in England and Wales as a whole. To calculate a PMR the proportion of deaths in the general population from suicide is needed. This proportion is applied to the number of deaths in the occupation group being considered to produce an expected number of deaths from suicide. The ratio of the actual number to the expected number is multiplied by 100 to give the PMR. A PMR of 100 means that there is no difference in the ratio of suicide deaths to all deaths in the given occupation compared with the general population of England and Wales. A value of 50 means that the chances of a death in a given occupation being due to suicide are half that of the general population of England and Wales as a whole, whereas a value of 200 means that the given occupation has double the proportion of all deaths certified as suicide than would be expected from the proportion of the general population in England and Wales. 
Standardised mortality ratios are also an indirect method of age standardisation. Age-specific death rates in a standard population are applied to the age structure of the occupation group being considered to calculate an expected number of deaths in that occupation group. The ratio of the observed number of deaths to the expected number of deaths in the group is calculated and multiplied by 100 to give the SMR. An SMR under or over 100 indicates lower or higher mortality in the occupation group compared with the general population.

Table 1 presents PMRs and SMRs for the highest level of grouping, which consists of nine broad occupational groups plus students and those in full-time education. Online Tables DS1 and DS2 present data for three-digit occupational codes, which can be thought of as job groups, and Tables DS3 and DS4 present the four-digit classification which describes occupation at the finest level of detail. Suicide PMRs (together with the corresponding SMRs) are presented in these tables for those occupations whose rates were significantly higher than expected in 2001-2005, that is, where the 95\% confidence interval excluded 100.

The data in Tables DS1-DS4 are not ordered by the value of their PMR but by their confidence intervals. The occupations with the highest ratio of those analysed are presented in descending order of the lower confidence interval. This means that the occupations with PMRs most significantly different from those for the general population of England and Wales are always presented at the top of the tables. This method of ordering PMRs has the advantage of taking account of the statistical variability as well as the magnitude of the PMR. ${ }^{23}$

\section{Results}

\section{Suicide mortality rates $2001-2005$}

In 2001-2005 the highest PMRs among men were found in a number of broad occupational groups. However, when the SMR was examined, only those in skilled trades and in elementary occupations stood out as having significantly higher mortality than the general population. The major group of skilled trades covers occupations whose tasks involve the performance of complex physical duties that normally require a degree of initiative, manual dexterity and other practical skills. The main tasks of these occupations require experience with, and understanding of, the work situation, the materials worked with, and the requirements of the structures, machinery and other items produced. Elementary occupations are those which require the knowledge and experience necessary to perform mostly routine tasks, often involving the use of simple hand-held tools and, in some cases, requiring a degree of physical effort and do not require formal educational qualifications.

Some groups with high PMRs, such as professional occupations, had low SMRs. In this case, it is likely that low mortality from other causes of death makes suicide stand out as an important cause of death for this group, even though their mortality from suicide is lower than that for the general population. For women, every occupational group had lower SMRs than women in general in England and Wales, implying a protective effect of being in an occupation, whatever that occupation is. Again, as for men, a number of occupational groups had PMRs above 100 (Table 1).

In 2001-2005, those working as health professionals had among the highest suicide PMRs for both men and women: 164 (95\% CI 133-201) among men and 232 (95\% CI 167-315) among women (Tables DS1 and DS2). This indicates that suicide is an important cause of death in this occupational group compared with other causes. However, the SMR for men was below 100, indicating lower suicide mortality than the general population. For women, however, the SMR was 142 (95\% CI 102-193), indicating significantly higher mortality than the general population for women health professionals. The more detailed occupational grouping presented in Tables DS3 and DS4 shows that the main contributors to the high PMRs among health professionals were male dental practitioners $(\mathrm{PMR}=292,95 \%$ CI 173-461), medical practitioners of both genders (male PMR $=165$, 95\% CI 125-214; female $\mathrm{PMR}=264,95 \%$ CI 171-390) and female veterinarians $(\mathrm{PMR}=609$, 95\% CI 198-1422). Nurses of both genders also had significantly high PMRs. The SMR for male dental practitioners and nurses was not significantly different from 100 and for male medical practitioners the SMR indicated lower

\begin{tabular}{|c|c|c|c|}
\hline & Suicides, $n$ & $\operatorname{SMR}(95 \% \mathrm{Cl})$ & PMR $(95 \% \mathrm{Cl})$ \\
\hline \multicolumn{4}{|l|}{ Men aged 20-64 years } \\
\hline Managers and senior officials & 963 & 37 (37-37) & $76(76-76)$ \\
\hline Professional occupations & 804 & $48(44-51)$ & $104(96-111)$ \\
\hline Associate professional and technical occupations & 1231 & $66(66-66)$ & $103(103-104)$ \\
\hline Administrative and secretarial occupations & 413 & $54(49-60)$ & 85 (77-94) \\
\hline Skilled trades occupations & 3213 & $118(118-118)$ & $101(101-101)$ \\
\hline Personal service occupations & 305 & $104(92-116)$ & $101(90-113)$ \\
\hline Sales and customer service occupations & 290 & $61(54-68)$ & $102(91-115)$ \\
\hline Process, plant and machine operatives & 1885 & $94(94-94)$ & $96(96-96)$ \\
\hline Elementary occupations & 2244 & $128(128-128)$ & $103(103-104)$ \\
\hline Students and full-time education & 288 & - & $98(87-110)$ \\
\hline \multicolumn{4}{|l|}{ Women aged $20-64$ years } \\
\hline Managers and senior officials & 167 & $37(31-43)$ & $70(60-82)$ \\
\hline Professional occupations & 253 & $63(55-71)$ & $110(97-124)$ \\
\hline Associate professional and technical occupations & 432 & $79(71-86)$ & $122(111-134)$ \\
\hline Administrative and secretarial occupations & 543 & $56(52-61)$ & $93(85-101)$ \\
\hline Skilled trades occupations & 90 & $79(63-97)$ & $93(74-114)$ \\
\hline Personal service occupations & 415 & $76(69-84)$ & $102(92-112)$ \\
\hline Sales and customer service occupations & 234 & $47(41-54)$ & $102(90-116)$ \\
\hline Process, plant and machine operatives & 94 & $55(44-67)$ & $77(63-95)$ \\
\hline Elementary occupations & 361 & $62(55-68)$ & $115(104-128)$ \\
\hline Students and full-time education & 107 & - & $121(99-146)$ \\
\hline
\end{tabular}




\begin{tabular}{|c|c|c|c|}
\hline Period & Age, years & SMR & Deaths, $n$ \\
\hline \multicolumn{4}{|l|}{ England and Wales } \\
\hline 1949-1953 & $20-64$ & 226 & 61 \\
\hline 1959-1963 & $15-64$ & 176 & 65 \\
\hline 1970-1972 & $15-64$ & 335 & 55 \\
\hline \multicolumn{4}{|l|}{ Great Britain } \\
\hline 1979-1980, 1982-1983 & $20-64$ & 172 & 65 \\
\hline \multicolumn{4}{|l|}{ England and Wales } \\
\hline 2001-2005 & $20-64$ & 69 & 58 \\
\hline
\end{tabular}

mortality than the general population. The SMRs for female veterinarians was significantly greater than 100 , indicating higher suicide mortality than the general population in this group, but this was based on a small number of suicides. For female medical practitioners and nurses of both genders, the SMR was higher than 100 , but was not statistically significant.

The second most significantly high PMR for the three-digit group for males was for agricultural trades (PMR $=133,95 \% \mathrm{CI}$ 119-147) (Table DS1). This includes farmers, who had a PMR of 189 (95\% CI 157-227) (Table DS3). The SMRs for these groups were also significantly higher than 100 , indicating higher suicide mortality than the general population. The third highest PMR among men were beauticians and related workers (defined as those who give facial and body beauty treatments, apply cosmetics and dress wigs, comprising manicurists, make-up artists and slimming consultants).

Among women, those participating in sports and fitness occupations had both a high PMR and SMR but these ratios are based on a small number of suicides.

\section{Comparisons with earlier studies}

It is difficult to make direct comparisons with previous studies, because the classification of occupations has changed and the measure used (PMR) is not directly comparable across time periods. However, broad patterns can be drawn out. Among men (Table DS5) dental practitioners had high PMRs in 19821987 (PMR=192), 1991-1996 (PMR=249) and 2001-2005 $(\mathrm{PMR}=292)$. Farmers and medical practitioners were also represented in the occupations with the highest suicide PMRs across the three decades (farmers: 1982-1987, PMR $=202$; 1991-1996, PMR $=144$; 2001-2005, PMR=189; medical practitioners: 19821987, $\mathrm{PMR}=175 ;$ 1991-1996, $\mathrm{PMR}=147 ;$ 2001-2005, $\mathrm{PMR}=165$ ).

Among women (Table DS6), medical practitioners, waitresses and nurses had high PMRs (355, 285, 264; 148, 187, 168; and 146 137,141 respectively) in each of the three time periods. Women classified as students had significantly high PMRs in the 1980s and 1990s - 144 and 139 respectively - based on relatively large numbers of deaths. In 2001-2005 the PMR for women students was above $100 \quad(\mathrm{PMR}=121,95 \%$ CI 99-146) but was not statistically significant (Table 1).

The pattern for male doctors is unusual. In the past, both PMRs and SMRs for male doctors have been above 100 (Table 2 ), indicating both high suicide mortality in relation to other causes of death for male doctors and higher suicide mortality than the general population. However, in the most recent data presented for the first time here, male doctors have a lower SMR, indicating lower suicide mortality than the general population.

\section{Discussion}

The absolute number of suicides in each occupational group often reflects the number of people working in those populations; hence, among men the most suicides occur among construction workers, machine and plant operatives and van drivers. What this analysis has demonstrated is that, as in the 1980s, in certain occupational groups suicide is a much more important cause of death than other causes. There has broadly been consistency about which occupational groups are at highest risk, albeit with some intriguing changes over the decades. Thus, the groups with the highest suicide rates relative to other causes of death throughout the decades remain health professional and agricultural occupations, suggesting a link between occupation and access to, and knowledge of, methods of taking one's own life. It is interesting to note that for male doctors, however, suicide mortality was lower than the general population (based on the SMR), when in past years it has been shown to be higher. This is a similar finding to Hawton $e t a l,{ }^{25}$ although they used a different population basis to calculate the SMR - the National Health Service workforce rather than all doctors from census returns as used here. Lindeman et al $^{26}$ demonstrated that in several countries suicide rates tend to be elevated in female doctors and much closer to average population rates in male doctors.

A raised PMR does not necessarily represent an excess suicide mortality rate for that occupational group. It only represents an excess proportion of deaths from suicide compared with other causes. For example, students are predominantly young in age so the likelihood of them dying from any cause is very low. If they do die it is more likely to be from external causes of death such as suicides or accidents than from natural causes. As a result, an observed excess may represent a true difference, but may also simply represent a deficit of deaths from other causes. This is seen in our analysis where male doctors have a PMR above 100 but an SMR below 100 .

However, the PMR does have the advantage over the SMR that it is free of numerator/denominator bias, as all data come from the same source (the death certificate). The SMR has the advantage that it gives a mortality rate for the occupation group compared with the general population that is unaffected by mortality from other causes in that particular occupation group. However, because it requires population data from census returns, it can be subject to numerator/denominator bias, particularly for women, and can only be calculated around census years. The problems of differences between census occupation and occupation recorded at death registration have been well documented. ${ }^{24}$ Neither the PMR nor the SMR allows for the analysis of trends over time, since both are relative measures based at a set time point. Thus, an SMR for male doctors of 172 around the 1981 Census compared with an SMR of 69 around the 2001 Census only informs us about the position of male doctors relative to the general population of England and Wales - higher mortality in 1981 and lower mortality in 2001. It does not tell us whether or not absolute rates in male doctors have increased, decreased or remained stable. Similarly, a PMR of 192 in 1982-1987 and 292 in 2001-2005 for male dentists only informs us that the proportion of all deaths due to suicide in dentists has changed relative to the proportion in England and Wales. It does not tell us whether suicide rates in male dentists have increased, decreased or remained stable.

Jenkins $^{27}$ and Singh ${ }^{28}$ proposed a pathway to suicide starting from stressful life events and lack of social supports, to depressive thoughts and suicidal ideation, to seeking the means of suicide and then to suicide itself. Recent studies have indicated that 
mental illness and social factors independently contribute to the risk of suicidal behaviour ${ }^{29}$ and suicide. ${ }^{30}$ Many factors influence this pathway to suicide, including factors which influence rates of life events, availability of social supports, rates of illness, knowledge of and access to healthcare and social interventions, knowledge of and access to means of suicide, and the behaviour of the media.

Both health professionals and agricultural occupations do have increased knowledge of and access to methods of suicide. The detailed results indicate particular occupational groups where further efforts are required to reduce suicide rates. The results for male medical practitioners deserve further exploration. For example, an epidemiological survey of the prevalence of depression and suicidal ideation in male and female medical practitioners could be carried out together with prevalence of life events, assessment of social network size and perceived social support, to examine whether male medical practitioners experience lower rates of depression and suicidal ideation and their antecedents than female medical practitioners. Comparisons may also be made with the national psychiatric morbidity survey data to see whether male medical practitioners experience lower rates of the above than the general population.

\section{Policy implications}

Construction industries employ a large number of men and within this group of workers there is a large number of suicides and a significantly high PMR and SMR. All of these measures are helpful in indicating further potential for targeted suicide prevention strategies. These include measures for increasing resilience, reducing life events and social adversity in these high-risk occupations, as well as enhancing availability and use of health and social care, specific competency training of health and social care professionals in touch with these occupational groups (especially primary care), reducing access to the means of suicide, reducing access to alcohol (which is a key facilitating factor for suicide) and media codes of conduct on suicide reporting. The data reported in this paper indicate that although there have been a number of initiatives in all of the above areas, as part of national suicide prevention strategies, ${ }^{31-35}$ excess mortality from suicide still remains in some groups.

Howard Meltzer, PhD, Department of Health Sciences, University of Leicester, Leicester; Clare Griffiths, MSC, Anita Brock, Cleo Rooney, MBBS, MSC, MFPH, Mortality Statistics, Office for National Statistics, London; Rachel Jenkins, MD, MA MB, BChir(Cantab), FRCPsych, FAPA, FFOMM, MFPH, World Health Organization Collaborating Centre for Mental Health, Institute of Psychiatry, London, UK

Correspondence: Professor Howard Meltzer, Department of Health Sciences, University of Leicester, Leicester LE1 6TP, UK. Email: hm74@leicester.ac.uk

First received 18 May 2007, final revision 13 Dec 2007, accepted 15 Jan 2008

\section{References}

1 Shepherd DM, Barraclough BM. Work and suicide: an empirical investigation Br J Psychiatry 1980; 136: 469-78.

2 Gunnell D, Harbord R, Singleton N, Jenkins R, Lewis G. Factors influencing the development and amelioration of suicidal thoughts in the general population. Cohort study. Br J Psychiatry 2004; 185: 385-93.

3 Lewis G, Sloggett A. Suicide, deprivation and unemployment: record linkage study. BMJ 1998; 317: 941-2.

4 Blakely TA, Collings SC, Atkinson J. Unemployment and suicide. Evidence for a causal association? J Epidemiol Community Health 2003; 57: 594-600.

5 Charlton J, Kelly S, Dunnell K, Evans B, Jenkins R. Trends in suicide deaths in England and Wales. Popul Trends 1992; 69: 10-6.

6 Charlton J, Kelly S, Dunnell K, Evans B, Jenkins R. Suicide trends in England and Wales: trends in factors associated with suicide deaths - part two. Popul Trends 1993; 71: 34-42.
7 Kelly S, Charlton J, Jenkins R. Suicide deaths in England and Wales, 19821992: the contribution of occupation and geography. Popul Trends 1995; 80: 16-25.

8 Charlton J. Trends and patterns in suicide in England and Wales. Int $J$ Epidemiol 1995; 24 (suppl 1): S45-52.

9 Kelly S, Bunting J. Trends in suicide in England and Wales, 1982-96. Popul Trends 1998; 92: 29-41.

10 Hawton K, Malmberg A, Simkin S. Suicide in doctors. A psychological autopsy study. J Psychosom Res 2004; 57: 1-4.

11 Seagrott V, Rooney C. Suicide in doctors. BMJ 1993; 307: 447

12 Richings JC, Khara GS, McDowell M. Suicide in young doctors. Br J Psychiatry 1986; 149: 475-8.

13 Hawton K, Simkin S, Rue J, Haw C, Barbour F, Clements A, Sakarovitch C, Deeks J. Suicide in female nurses in England and Wales. Psychol Med 2002; 32: 239-50.

14 Hawton K, Fagg J, Simkin S, Harriss L, Malmberg A, Smith D. The geographical distribution of suicides in farmers in England and Wales. Soc Psychiatry Psychiatr Epidemiol 1999; 34: 122-7.

15 Fear NT, Williamson S. Suicide and Open Verdict Deaths among Males in the UK Regular Armed Forces. Comparison with the UK Civilian Population and the US Military. Defence Analytical Services Agency, 2003.

16 Collins IP, Paykel ES. Suicide amongst Cambridge University students 19701996. Soc Psychiatry Psychiatr Epidemiol 2000; 35: 128-32.

17 Hawton K, Simkin S, Fagg J, Hawkins M. Suicide in Oxford University students, 1976-1990. Br J Psychiatry 1995; 166: 44-50.

18 Stack S. Gender and suicide risk among artists: a multivariate analysis. Suicide Life Threat Behav 1996; 26: 374-9.

19 Preti A, De Biasi F, Miotto P. Musical creativity and suicide. Psychol Rep 2001; 89: 719-27.

20 Brock A, Griffiths $C$. Trends in suicide by method in England and Wales, 1979-2001. Health Stat Q 2003; 20: 7-18.

21 World Health Organization. The ICD-10 Classification of Mental and Behavioural Disorders: Clinical Descriptions and Diagnostic Guidelines. WHO, 1992.

22 Office for National Statistics. Standard Occupational Classification, Volumes 1 and 2. TSO (The Stationery Office), 2000

23 Roman E, Carpenter L. Cancer incidence in England, 1981-1987. In Occupational Health Decennial Supplement. Series DS No.2 (ed F. Driver). TSO (The Stationery Office), 1995.

24 Office of Population Censuses and Surveys. Occupational Mortality: 1979-80, 1982-83. Series DS No. 6. TSO (The Stationery Office), 1986.

25 Hawton K, Clements A, Sakarovitch C. Suicide in doctors: a study of risk according to gender, seniority and specialty in medical practitioners in England and Wales, 1979-1995. J Epidemiol Community Health 2001; 55 296-300.

26 Lindeman S, Laara E, Hakko H, Lonnqvist J. A systematic review on gender-specific suicide mortality in medical doctors. Br J Psychiatry 1996; 168: $274-9$.

27 Jenkins R, Singh B. General population strategies of suicide prevention. In The International Handbook of Suicide and Attempted Suicide (eds K Hawton \& $\mathrm{K}$ van Heeringen). John Wiley \& Sons

28 Jenkins $\mathrm{R}$, Singh B. Policy and practice in suicide prevention. Br J Forensic Pract 2000; 2: 3-11.

29. Jenkins $R$, Bhugra $D$, Meltzer $H$, Singleton $N$, Bebbington $P$, Brugha $T$, Coid J, Farrell M, Lewis G, Paton J. Psychiatric and social aspects of suicidal behaviour in prisons. Psychol Med 2005; 35: 257-69.

30 Appleby L, Cooper J, Amos T, Faragher B. Psychological autopsy study of suicides by people aged under 35. Br J Psychiatry 1999; 175: 168-74.

31 Department of Health. National Suicide Prevention Strategy for England. Department of Health, 2002.

32 Department of Health. National Suicide Prevention Strategy for England: Annual Report on Progress. Department of Health, 2004.

33 Care Services Improvement Partnership. National Suicide Prevention Strategy for England: Annual Report on Progress. National Institute for Mental Health in England, 2005.

34 Health Service Executive, National Suicide Review Group, Department of Health and Children. National Strategy for Action on Suicide Prevention 2005-2014. Health Service Exectutive, 2005

35 Scottish Executive. Choose Life: A National Strategy and Action Plan to Prevent Suicide in Scotland. Scottish Executive Publications, 2002. 